JIPPF, Vol. 1, Edisi 1, Halaman: 39-43

\title{
PENERAPAN MODEL PEMBELAJARAN DISCOVERY LEARNING TERHADAP KETERAMPILAN PROSES SAINS SISWA PADA MATERI LISTRIK DINAMIS DI KELAS IX SMP NEGERI 7 SUNGAI RAYA
}

\author{
${ }^{1 *}$ Arlisa, ${ }^{2}$ Dwi Fajar Saputri, ${ }^{3}$ Boisandi \\ 1 SMA Negeri 9, Jln Tanjung Raya II, Pontianak, Indonesia \\ 2 IKIP PGRI Pontianak, JIn Ampera No. 88, Pontianak, Indonesia \\ ${ }_{3}^{3}$ IKIP PGRI Pontianak, JIn Ampera No. 88, Pontianak, Indonesia
}

Email Korespondensi: arlisa.lisa997@gmail.com

INFO ARTIKEL

Diterima 00 Maret 2020

Dipublikasikan 00 Agustus 2020

\begin{abstract}
A B STRACT
This study aims to obtain an objective clarity regarding the application of discovery learning models to students' science process skills in dynamic electrical material for class IX students of SMP Negeri 7 Sungai Raya. This research method uses the Quasi Experiment Design method with the research design is Posttest-Only Nonequivalent Groups. Data collection techniques are essay tests to measure students' science process skills. The population in this study were all grade IX students of SMP Negeri 7 Sungai Raya consisting of 4 classes. The sample in this study were students of SMP Negeri 7 Sungai Raya in class IX B and class IX C in the odd semester of the 2019/2020 school year, taken by cluster random sampling. Analysis of the data description using the average equation (mean), analysis of the hypothesis test using the $U$ Maan Whitney test. The results of this study indicate that 1) the students' science process skills after applying the direct learning model to the dynamic electrical material of class IX students of SMP Negeri 7 Sungai Raya is classified as not good at $62.67 ; 2$ ) students' science process skills after the discovery learning model applied to the dynamic electrical material of class IX students of SMP Negeri 7 Sungai Raya is classified as good, amounting to 81.07; 3) there are differences in the science process skills of students who are taught using discovery learning models and students who are taught using direct learning models on dynamic electrical material for class IX students of SMP Negeri 7 Sungai Raya.

Keywords: Student Science Process Skills, Discovery Learning
\end{abstract}

\section{Latar Belakang}

Pendidikan adalah usaha sadar dan terencana untuk mewujudkan suasana belajar dan proses pembelajaran agar peserta didik secara aktif mengembangkan potensi dirinya untuk memiliki kekuatan spiritual keagamaan, pengendalian diri, kepribadian, kecerdasan, akhlak mulia, serta keterampilan yang diperlukan dirinya, masyarakat bangsa dan Negara (UU No. 20 tahun 2013).

Salah satu pelajaran penting yang harus dikuasai siswa adalah Pengetahuan Alam (IPA). Ilmu Pengetahuan Alam (IPA) adalah pengetahuan tentang dunia alamiah yang meliputi tiga bidang ilmu dasar, yaitu biologi, fisika dan kimia. IImu Pengetahuan Alam (IPA) berkaitan dengan cara mencari tahu tentang alam secara sistematis sehingga IPA bukan hanya penguasaan kumpulan pengetahuan berupa fakta-fakta, knsep-konsep, atau prinsip- prinsip saja, tetapi juga merupakan suatu proses penemuan. Pendidikan IPA diharapkan dapat menjadi wahana bagi peserta didik untuk mempelajari diri sendiri dan alam sekitar, serta prospek pengembangan lebih lanjut dalam penerapannya didalam kehidupan sehari- hari. Proses pembelajaran menekankan pada pemberian pengamalan langsung untuk mengembangkan kompetensi agar menjajahi dan memahami alam sekitar secara ilmiah (Hardini, 2011:149).

Berdasarkan hasil wawancara dengan guru IPA SMP Negeri 7 Sungai Raya diperoleh informasi bahwa hasil belajar siswa pada materi listrik dinamis belum mencapai kriteria ketuntasan minimum (KKM) yaitu 70. Persentase siswa masih dibawah 50\%. Hal ini menunjukkan bahwa banyak siswa yang mengalami kesulitan dalam belajar terutama pada materi listrik dinamis yang mencerminkan bahwa adanya ketidakberhasilan suatu pembelajaran yang diberikan. Padahal, dari 
hasil wawancara guru diperoleh informasi bahwa guru telah melakukan variasi dalam pembelajaran seperti menggunakan metode demonstrasi, ceramah, dan tanya jawab. Keterampilan proses sains sangat berpengaruh terhadap perkembangan berfikir siswa yang akan berpengaruh juga terhadap hasil belajarnya. Materi pelajaran akan lebih mudah dipelajari, dipahami, dihayati, dan diingat jika siswa memperoleh pengalaman langsung dari peristiwa belajar tersebut melalui pengamatan atau eksperimen. Untuk itu dibutuhkan suatu model pembelajaran IPA yang dapat melatih keterampilan proses sains siswa, maka digunakan model pembelajaran discovery learning. Model discovery learning merupakan proses pembelajaran yang didasarkan pada penemuan melalui proses berpikir secara sistematis. Sintak model discovery learing yaitu stimulasi, mengidentifikasi masalah, mengumpulkan data, mengolah data, pembuktian, dan merumuskan kesimpulan. Sintak dalam pembelajaran discovery learning sangat sesuai dalam mengembangkan keterampilan proses sains siswa.

Berdasarkan uraian diatas maka dapat dilakukan penelitian dengan menerapkan model discovery learning terhadap keterampilan proses sains suswa pada materi listrik dinamis kelas IX SMP Negeri 7 Sungai Raya.

\section{Metodologi}

Metode penelitian yang digunakan dalam penelitian ini adalah metode eksperimen. Bentuk penelitian yang digunakan adalah Quasi Eksperimen Design dengan rancangan penelitian Nonequivalen Groups Posttest Only. populasi dalam penelitian ini adalah seluruh siswa kelas IX SMP Negeri 7 Sungai Raya yang terdiri dari empat kelas. Teknik pengambilan sampel yang digunakan dalam penelitian ini yaitu teknik probability sampling. Dari beberapa teknik probability sampling, peneliti menggunakan teknik cluster random sampling dan uji homogenitas populasi menggunakan uji Bartlett. Analisis deksripsi data posttest dengan menggunakan persamaan rata-rata(mean), analisis uji hipotesis dengan menggunakan uji U Maan Whitney.

\section{Hasil dan Pembahasan}

\subsection{Hasil Penelitian}

Hasil keterampilan proses sains siswa dianalisis dengan menggunakan statistik deskriptif. Perbedaan keterampilan proses sains siswa kelas kontrol dan kelas eksperimen dapat dilihat pada tabel 1

Tabel 1. Perbedaan keterampilan proses sains siswa berdasarkan tiap aspek kelas eksperimen dan kelas kontrol

\begin{tabular}{lll}
\hline Aspek KPS & Eksperimen & Kontrol \\
\hline Mengamati & 64.28 & 72.22 \\
\hline Memprediksi & 65.34 & 58.64 \\
\hline Menyimpulkan & 78.27 & 55.86 \\
\hline Mengkomunikasikan & 78.86 & 51.23 \\
\hline Mengklasifikasikan & 100 & 69.14 \\
\hline Mengukur & 90.4 & 74.77 \\
\hline
\end{tabular}

Tabel 2. Perbedaan Keterampilan Proses Sains Siswa berdasarkan rata-rata Kelas Eksperimen dan Kelas Kontrol

\begin{tabular}{ccc}
\hline & Kelas Eksperimen & Kelas Kontrol \\
\hline Jumlah Siswa & 28 & 27 \\
\hline Nilai Minimum & 67 & 27 \\
\hline
\end{tabular}

JIPPF, Vol. 1, Edisi 1, Halaman: 39-43 


\begin{tabular}{ccc}
\hline Nilai Maksimum & 89 & 82 \\
\hline Nilai Ideal & 100 & 100 \\
\hline Nilai Rata-rata & 81.07 & 62.67 \\
\hline Kriteria KPS & Sangat Baik & Cukup \\
\hline
\end{tabular}

Berdasarkan tabel 1 dapat diketahui bahwa nilai minimum pada kelas kontrol adalah 27, sedangkan nilai maksimumnya adalah 82. Untuk kelas eksperimen nilai minimumnya sebesar 67 dan nilai maksimumnya sebesar 89. Nilai ideal dari kedua kelas yaitu kelas eksperimen dan kelas kontrol adalah 100. Adapun nilai rata-rata untuk kelas kontrol adalah 62.67 sedangkan kelas eksperimen adalah 81,07. Jadi dapat disimpulkan bahwa keterampilan proses untuk kelas kontrol masing tergolong kurang dan keterampilan proses sains siswa untuk kelas eksperimen tergolong baik dan terdapat perbedaan keterampilan proses sains siswa antara yang di ajarkan menggunakan model pembelajaran langsung dan dengan diajarkan menggunakan model pembelajaran discovery learning.

Uji prasyarat meliputi uji normalitas data. Rekapitulasi uji prasyarat disajikan pada tabel 2.

Tabel 3. Hasil Uji Normalitas Data

\begin{tabular}{cccc}
\hline Kelas Penelitian & $\boldsymbol{x}^{\mathbf{2}}$ hitung & $\boldsymbol{x}^{\mathbf{2}}$ Tabel $(\alpha=5 \%)$ & Kesimpulan \\
\hline Kelas Eksperimen & 16.420 & 11.07 & $\begin{array}{c}\text { Data tidak berdistribusi normal karena } \\
\left(x^{2} \text { hitung }\right)>\left(x^{2} \text { Tabel }\right)\end{array}$ \\
\hline Kelas Kontrol & 29.09 & 11.07 & Data tidak berdistribusi normal karena \\
$\left(x^{2}\right.$ hitung $)>\left(x^{2}\right.$ Tabel $)$
\end{tabular}

Karena kedua data tidak berdistribusi normal, maka untuk menguji statistik yang digunakan adalah statistik non paramentrik yaitu uji U Maan Whitney.

Jumlah sampel dalam penelitian ini lebih dari 20 siswa maka dilakukan pendekatan normal uji Z. adapun uji U Maan Whitney dimuat dalam tabel 3.

Tabel 4. Hasil Uji Hipotesis

\begin{tabular}{crrl}
\hline Z Hitung & Z Tabel & \multicolumn{1}{c}{ Keterangan } & \multicolumn{1}{c}{ Kesimpulan } \\
\hline$-13,33$ & \pm 1.96 & $\begin{array}{l}\text { Ho ditolak jika }-Z \\
\text { hitung } \leq \text { Z tabel }\end{array}$ & $\begin{array}{l}\text { Karena Z Hitung tidak terletak pada daerah } \\
\text { penerimaan Ho maka Ho ditolak atau Ha di } \\
\text { terima }\end{array}$ \\
& & &
\end{tabular}

Berdasarkan uji U Maan Whitney diperoleh $Z_{\text {hitung }}=13,33$ dan $Z_{\text {tabel }}= \pm 1.96$ dengan $\alpha=5 \%$ maka $Z_{\text {hitung }}$ tidak terletak padPa daerah penerimaan Ho, maka Ho ditolak. Sehingga dapat disimpulkan bahwa terdapat perbedaan keterampilan proses sains siswa yang diajarkan menggunakan model pembelajaran discovery learning dan siswa yang diajar menggunakan model pembelajaran langsung pada materi listrik dinamis siswa kelas IX SMP Negeri 7 Sungai Raya.

\subsection{Pembahasan Penelitian}

Berdasarkan data pada tabel 1 dan 2 dapat dilihat bahwa keterampilan proses sains siswa pada kelas eksperimen lebih baik dibandingkan kelas kontrol. Rata-rata keterampilan proses sains siswa pada kelas eksperimen tergolong sangat baik, sedangkan pada kelas kontrol keterampilan proses sains siswa masing tergolong cukup. Demikian pula jika dilihat pada tiap aspek-aspek keterampilan proses sains siswa pada kelas eksperimen lebih baikjika dibandingkan dengan kelas kontrol. Hal ini menunjukkan bahwa secara umum terdapat perbedaan keterampilan proses sains siswa yang diajarkan 
menggunakan model pembelajaran discovery learning dan siswa yang diajarkan menggunakan model pembelajaran langsung.

Hasil uji hipotesis dengan uji U Maan Whitney menunjukkan bahwa terdapat perbedaan keterampilan proses sains siswa yang diajarkan menggunakan model pembelajaran discovery learning dan siswa yang diajarkan dengan model pembelajaran langsung Pada materi listrik dinamis siswa kelas IX SMP Negeri 7 Sungai Raya. Adanya perbedaan keterampilan proses sains siswa yang diajarkan menggunakan model pembelajaran discovery learning disebabkan tahapan - tahapan pada model pembelajaran discovery learning dapat digunakan untuk melatih keterampilan proses sains siswa yaitu keterampilan mengamati, memprediksi, mengukur, mengklasifikasikan, mengkomunikasikan dan menyimpulkan. Hasil yang diperoleh dalam penelitian ini sejalan dengan penelitian terdahulu yang menunjukkan bahwa penerapan model pembelajaran Discovery Learning berpengaruh pada keterampilan proses sains siswa pada mata pelajaran IPA siswa kelas VIII SMP Advend Palu

\section{Kesimpulan}

Berdasarkan pengolahan data dan analisis data, maka dapat disimpulkan secara umum terdapat perbedaan keterampilan proses sains siswa yang di ajar menggunakan model pembelajaran discovery learning pada materi listrik dinamis siswa kelas IX SMP Negeri 7 Sungai Raya. Adapun kesimpulan secara khusus bahwa Keterampilan proses sains siswa setelah diterapkan model pembelajaran langsung pada materi listrik dinamis di SMP Negeri 7 Sungai Raya tergolong kurang yaitu sebesar 62.67

Keterampilan proses sains siswa setelah diterapkan model pembelajaran discovery learning pada materi listrik dinamis di SMP Negeri 7 Sungai Raya tergolong kurang yaitu sebesar 81.07

Terdapat perbedaan keterampilan proses sains siswa yang diajarkan menggunakan model pembelajaran discovery learning dan model pembelajaran langsung pada materi listrik dinamis siswa kelas IX SMP Negeri 7 Sungai Raya

\section{Referensi}

Direktorat Pembina SMA. (2015). Model-model PembelajaranPelatihanKurikulum 2013. Jakarta: KEMDIKBUD.

Hardini, Srianidkk. (2011). Strategi Pembelajaran Terpadu. Yogyakarta: Familia.

Semiawan, C. dkk (1984). Pendekatan Keterampilan Proses. Jakarta: PT Gramedia.

Susanti, Eva (2016). Pengaruh Model Pembelajaran Discovery Learning Terhadap Keterampilan Proses Sains Siswa dan Hasil Belajar Siswa Kelas VIII IPA SMP Advend Palu. Jurnal Sains dan Teknologi,4(3) 36-14

JIPPF, Vol. 1, Edisi 1, Halaman: 39-43 